\title{
Orientation-dependent chemistry and band-bending of Ti on polar ZnO surfaces
}

\author{
P. Borghetti, ${ }^{1}$ Y. Mouchaal, ${ }^{1,2,{ }^{*}}$ Z. Dai, ${ }^{1}$ G. Cabailh, ${ }^{1}$ S. Chenot,${ }^{1}$ R. Lazzari, ${ }^{1}$ and J. Jupille ${ }^{1}$ \\ ${ }^{1}$ Sorbonne Universités, CNRS-UMR 7588, UPMC Univ Paris 06, Institut des NanoSciences de Paris, \\ F-75005, Paris, France \\ 2 Laboratoire de Physique des Couches Minces et Matériaux pour l'Electronique (LPCMME), \\ Université d'Oran1 Ahmed Ben bella, BP 1524 EL M'Naouer 31000, Oran, Algeria \\ * Current address: Université Mustapha Stambouli de Mascara, Faculté des Sciences et de la \\ Technologie, BP 763, Mascara 29000, Algeria \\ E-mail: borghetti@insp.jussieu.fr
}

\begin{abstract}
Orientation-dependent reactivity and band-bending are evidenced upon Ti deposition (1-10 $\mathrm{A})$ on the polar $\mathrm{ZnO}(0001)-\mathrm{Zn}$ and $\mathrm{ZnO}(000 \overline{1})$-O surfaces. At the onset of the Ti deposition, a downward band-bending was observed on $\mathrm{ZnO}(000 \overline{1})-0$ while no change occurred on $\mathrm{ZnO}(0001)-\mathrm{Zn}$. Combining this with the photoemission analysis of the Ti $2 p$ core level and $\mathrm{Zn} \mathrm{L}_{3}\left(\mathrm{~L}_{2}\right) \mathrm{M}_{45} \mathrm{M}_{45}$ Auger transition, it is established that the $\mathrm{Ti} / \mathrm{ZnO}$ reaction is of the form $\mathrm{Ti}+2 \mathrm{ZnO} \rightarrow \mathrm{TiO}_{2}+2 \mathrm{Zn}$ on $\mathrm{ZnO}(0001)-\mathrm{Zn}$ and $\mathrm{Ti}+y \mathrm{ZnO} \rightarrow \mathrm{TiZn}_{x} \mathrm{O}_{y}+(y-x) \mathrm{Zn}$ on $\mathrm{ZnO}(000 \overline{1})-0$. Consistently, upon annealing thicker Ti adlayers, the metallic zinc is removed to leave $\mathrm{ZnO}(0001)-\mathrm{Zn}$ surfaces covered with $\mathrm{TiO}_{2^{-}}$ like phase and $\mathrm{ZnO}(000 \overline{1})-0$ surfaces covered with a defined ( $\mathrm{Ti}, \mathrm{Zn}, \mathrm{O})$ compound. Finally, a difference in the activation temperature between the O-terminated ( $500 \mathrm{~K}$ ) and $\mathrm{Zn}$-terminated (700 $\mathrm{K}$ ) surfaces is observed, which is tentatively explained by different electric fields in the space charge layer at $\mathrm{ZnO}$ surfaces.
\end{abstract}




\section{Introduction}

Mastering electrical contact of zinc oxide with metals ${ }^{1,2}$ is of prime interest in all the actual or potential uses of this semiconductor in optoelectronics and microelectronics ${ }^{3-5}$. Ohmic or Schottky contact are required depending on the type of device that is foreseen. Despite studies based on well-defined single crystals, the control of the barrier height at the metal/ZnO interface is far from being fully rationalized as it depends heavily on (i) surface orientation and polarity, (ii) metal reactivity and deposition method and (iii) annealing conditions. The barrier does not obey the ideal contact which should only be dominated by the affinity of the oxide and the work function of the metal ${ }^{1,2}$.

Probably due to the pinning of the Fermi level by interface or defect states, unreactive metal such as noble metals show a rectifying behaviour with a barrier height centred around $0.75 \mathrm{eV}$ independently of the metal work function. However, as a rule of thumb, the contact can be switched from Schottky to ohmic with reactivemetals, the oxides of which present a higher enthalpy ${ }^{1,2}$. Among the potential candidates that were explored, $\mathrm{Ti}$ is the one on which attention has been most focused either as deposited or as an alloying element of the contact layer ${ }^{1,2,6-12}$. Ti forms a very low barrier with $\mathrm{ZnO}$ both because of its low work function compared to electronic affinity of $\mathrm{ZnO}$ and of its high reactivity. It is believed that the interfacial reaction leads to a reduced $\mathrm{ZnO}$ subsurface enriched in O-vacancies which act as donors and increase the carrier concentration ${ }^{1,2,6}$. Next to its use to create ohmic contacts ${ }^{1,2,6-12}$, titanium is also known to promote adhesion for noble metals within optical coatings deposited on multilayeredglazings ${ }^{13-14}$, to enhance the gas sensor properties of $\mathrm{ZnO}^{15}$ and to set up resistive random access memories ${ }^{16}$. Changes in $\mathrm{Ti} / \mathrm{ZnO}$ stacking as a function of temperature are crucial regarding the optimization of contact resistivity ${ }^{1,2,6-12}$, gas detection limit ${ }^{17}$ and mechanical properties of coatings ${ }^{13}$. In all these fields, the interface chemistry is at the heart of the problem. But the detailed mechanism of interface reactivity and the role of the surface orientation in terms of species profile and chemical state are not yet resolved.

Regarding surface science approach of metal/polar-ZnO surfaces, little has been made to address the orientation-dependent chemistry and charge transfer at a reactive metal/ZnO interface. Most studies involving the polar $\mathrm{ZnO}(0001)$ and $\mathrm{ZnO}(000 \overline{1})$ surfaces have focused either on noble metals or on the end of the transition series: $\mathrm{Pt}^{18-22}, \mathrm{Pd}^{23}, \mathrm{Cu}^{24-30}, \mathrm{Ag}^{23,31,32}, \mathrm{Au}^{33}$. But dramatic transformations can occur with metals from the beginning and middle of the transition series, as illustrated by the formation of spinels upon annealing $\mathrm{Cr} / \mathrm{ZnO}(000 \overline{1})^{34,35}$ and $\mathrm{Fe} / \mathrm{ZnO}(0001)^{36}$ films and $\mathrm{ZnO} / \mathrm{Ti} / \mathrm{ZnO}$ coatings ${ }^{13}\left(\mathrm{ZnCr}_{2} \mathrm{O}_{4}, \mathrm{ZnFe}_{2} \mathrm{O}_{4}\right.$ and $\mathrm{Zn}_{2} \mathrm{TiO}_{4}$, respectively). Regarding $\mathrm{Ti}$, the chemical reactions at the interface of sputter-deposited $\mathrm{ZnO}$-Ti multilayers have been explored by hard $\mathrm{x}$-ray photoelectron spectroscopy, revealing the oxidation of $\mathrm{Ti}$ and the reduction of $\mathrm{ZnO}^{13,37}$. But the study was limited to (0001) oriented sputter-deposited polycrystalline ZnO films with no defined surface polarity ${ }^{37}$ which blurs the actual role of the termination. The orientation-dependent chemistry is expected to affect the reaction and inter-diffusion at the metal/ZnO interface. Indeed, the mechanisms of polarity healing are different between the two faces. In ultra-high vacuum conditions, the $\mathrm{Zn}$-terminated $\mathrm{ZnO}(0001)$ is stabilized by triangular features ${ }^{38}$ providing the required compensation charges through $\mathrm{Zn}$ vacancies. On the O-terminated $\mathrm{ZnO}(000 \overline{1})$, hydroxyl groups play an unmistakable role ${ }^{39}$ in polarity healing but the sub-stoichiometric reconstructions have recently been put forward ${ }^{40,41}$. 
At this stage, three sets of questions arise concerning: (i) the mechanism of the formation of the interface, which requires monitoring the growth from the early stages of the deposition, (ii) the chemical structure of interfaces, and (iii) the way the orientation affects properties. In the present work, the growth of ultrathin Ti films on the basal O-terminated $\mathrm{ZnO}(000 \overline{1})$ and Zn-terminated $\mathrm{ZnO}(0001)$ single crystal surfaces (referred as $\mathrm{Zn}-\mathrm{ZnO}$ and O-ZnO hereafter) is studied in a ultra-high vacuum chamber by $X$-ray photoemission spectroscopy (XPS) by scrutinizing the evolution of the $\mathrm{Ti}$

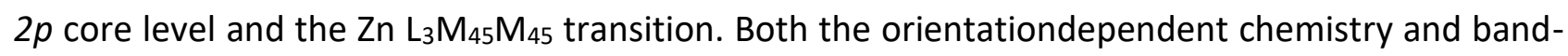
bending induced by $\mathrm{Ti}$ films and their behaviour upon annealing treatment are analysed. Angle dependent emission measurements also allow the determination of the depth profiles of chemical states.

\section{Experimental Section}

Experiments were carried out in a ultra-high vacuum chamber (base pressure $3 \times 10^{-8} \mathrm{~Pa}$ ) equipped with X-ray photoelectron spectrometer (XPS) and low energy electron diffraction device (LEED). Substrates provided by Tokyo Dempa were chemicomechanically polished and post-annealed above $1500 \mathrm{~K}$; they had a resistivity around a few ohms with a low content of Li impurities ${ }^{42}$. O-ZnO and $\mathrm{Zn}$-ZnO surfaces were prepared by cycles of $\mathrm{Ar}^{+}$-ion sputtering (kinetic energy $800 \mathrm{eV}$ ) followed by vacuum annealing ( $T=1100 \mathrm{~K}$ and $\mathrm{T}=1300 \mathrm{~K}$, respectively). The absence of surface contaminants was checked at the level of XPS sensitivity (a few \% of monolayer) while the surface crystallinity was indicated by sharp LEED $(1 \times 1)$ patterns ${ }^{39}$. Ti was deposited by electron beam evaporation from a Ti rod in ultra-high vacuum on $\mathrm{ZnO}$ substrates held at room temperature. The absolute deposition rate was calibrated using a quartz microbalance while keeping the evaporation flux constant. Thermal annealing of films was performed by electron-bombarding the back side of the Mo holder on which the $\mathrm{ZnO}$ samples were mounted. The annealing temperature was measured on the Mo plate by an optical pyrometer. XPS spectra were obtained using a non-monochromatic Al $\mathrm{K}_{\text {国 }}$ source photon energy of $\mathrm{h}$ ? = $1486.7 \mathrm{eV}$ ) and an Omicron EA 125 hemispherical analyzer at a pass energy of $20 \mathrm{~V}$.

Electron collection was either normal to the surface or grazing (take off angle $60^{\circ}$ ) to enhance the surface sensitivity of the measurement. If partial contamination by residual vacuum can never be fully ruled out, ageing of thick Ti films and oxygen uptake in $20 \mathrm{~h}$ turned out to be moderate. The fitting of Ti $2 p$ XPS spectra was done with CasaXPS software using a Shirley background ${ }^{43}$, a set of Voigt functions for the $\mathrm{Ti}^{4+}, \mathrm{Ti}^{3+}, \mathrm{Ti}^{2+}$ oxidation states and a Doniach-Sunjic line profile for the metallic $\mathrm{Ti}^{0}$ component. More details on the spectra fitting are given in the Electronic Supplementary Information (ESI).

\section{Reduction of $\mathrm{ZnO}$ at the interface with a Ti overlayer}

The O-ZnO and $\mathrm{Zn}$-ZnO surfaces were exposed to identical stepwise Ti depositions of nominal thicknesses $d_{\text {nom }}=1 \AA, 2 \AA, 4 \AA$ and $10 \AA$. The Ti deposition had dramatic effects on both surfaces. The total disappearance of the LEED patterns from the initial stages of the film growth $\left(d_{\text {nom }}=1 \AA\right.$ ) indicates the loss of the ZnO surface crystallinity and the lack of long-range order for the Ti films. In 
parallel, the XPS Ti $2 p$ spectra recorded at normal emission demonstrate the high reactivity of Ti on both polar surfaces (Fig. 1a). According to the binding energy (BE) position of the peaks (vertical dotted lines in Fig. 1a, more details can be seen in ESI), the dominant species at the lowest coverage is $\mathrm{Ti}^{4+}$. Upon increasing the Ti thickeness, the lower $\mathrm{Ti}$ oxidation states (from $\mathrm{Ti}^{3+}$ to $\mathrm{Ti}^{0}$ ) progressively appear and, starting from $d_{n o m}=4 \AA$, the $\mathrm{Ti}^{0}$ dominates the total composition of the $\mathrm{Ti}$ adlayer. The areas of the various Ti components obtained from the spectra fits (see ESI) have been plotted as a function of the total $\mathrm{Ti} 2 p$ area in Fig. $1 \mathrm{~b}$, which allows the definition of trends specific to each polar surface. For the same $d_{\text {nom, }}$ both the total Ti $2 p$ area and the $\mathrm{Ti} / \mathrm{Zn}$ area ratio (Fig. S1) are larger on $\mathrm{O}-\mathrm{ZnO}$ than on $\mathrm{Zn}-\mathrm{ZnO}$. Such a tendency does not depend on the evaporation sequence, since it is also observed when, instead of stepwise depositions, 2, 4, $10 \AA \mathrm{Ti}$ are deposited at once. In passing, this demonstrates the lack of strong effect of residual vacuum at the time scale of the measurements. Assuming the same sticking coefficient on both surfaces, the observation indicates a better Ti wetting on $\mathrm{O}-\mathrm{ZnO}$ than on $\mathrm{Zn}-\mathrm{ZnO}$, a trend which has already been observed for unreactive $\mathrm{Ag}^{31,32}$ and $\mathrm{Cu}^{26,28}$. Additionally, the value of the area of the $\mathrm{Ti}^{4+}$ component, which remains constant for all film thicknesses under study, is significantly higher on $\mathrm{Zn}-\mathrm{ZnO}$ than on $\mathrm{O}-\mathrm{ZnO}(\sim 25 \%)$. By contrast, the area of $\mathrm{Ti}^{0}$ tends to be slightly higher on $\mathrm{O}-\mathrm{ZnO}$ (Fig. 1b). The interaction of $\mathrm{Ti}$ with $\mathrm{ZnO}$ is likely complex. As demonstrated afterwards, the presence of all the $\mathrm{Ti}$ oxidation states and of metallic $\mathrm{Zn}$ on both surfaces as well as the absence of LEED patterns indicate that a partial etching of the $\mathrm{ZnO}$ surface occurs on both $\mathrm{Zn}-\mathrm{ZnO}$ and O-ZnO surfaces. The presence of hydroxyl groups and the specific reconstruction of each polar surface ${ }^{38-41}$ are expected to provide various local environments for Ti atoms. Nevertheless, the XPS spectra show clear orientation-dependent trends that are analyzed in what follows.

On both $\mathrm{ZnO}$ surfaces, the oxidation of $\mathrm{Ti}$ at the interface is accompanied by the reduction of $\mathrm{Zn}$. In the absence of sizeable core-level shift associated to the chemical state of zinc, $\mathrm{Zn}$ oxidation is efficiently tracked by means of the $\mathrm{Zn} \mathrm{L}_{3} \mathrm{M}_{45} \mathrm{M}_{45}$ Auger line, the most intense $\mathrm{Zn}$ LMM transition ${ }^{44-}$ ${ }^{46}$. In this transition, the core-hole in the $\mathrm{Zn} 2 p_{3 / 2}$ level $\left(L_{3}\right)$ is filled by an electron decaying from the $\mathrm{Zn} 3 \mathrm{~d}$ level $\left(\mathrm{M}_{45}\right)$, and the difference in energy between those two levels is used to emit an electron from the $\mathrm{Zn} 3 \mathrm{~d}$ level $\left(\mathrm{M}_{45}\right)$. The $\mathrm{Zn}_{3} \mathrm{M}_{45} \mathrm{M}_{45}$ profile is dominated by two intense features separated in energy by $\sim 3 \mathrm{eV}$ (peaks $A$ and $B$ in Fig. 2a). The oxidation of the metal results in a shift towards lower kinetic energy (KE) (or higher $B E$ ), a broadening of the $Z n$ LMM profile and a change in $A / B$ ratio ${ }^{44-46}$. Peak $A$ of pristine $\mathrm{ZnO}\left(\mathrm{A}_{o x}\right)$ and peak $\mathrm{B}$ of metallic $\mathrm{Zn}\left(\mathrm{B}_{\text {met }}\right)$ are separated in energy by $8 \mathrm{eV}$, which allows the identification and quantification of the oxidized states of $\mathrm{Zn}$ by means of templates recorded on $\mathrm{ZnO}$ surfaces and thick metallic $\mathrm{Zn}$ films ${ }^{44-46}$. In Fig. 2, Zn $\mathrm{L}_{3} \mathrm{M}_{45} \mathrm{M}_{45}$ spectra are decomposed into $\mathrm{ZnO}$ and $\mathrm{Zn}$ contributions by fitting with a linear combination of the above templates. Inspection of the Auger profile reveals (i) that for both $\mathrm{ZnO}$ surfaces, the relative intensity of the metallic component $\mathrm{B}_{\text {met }}$ grows as the Ti coverage increases and (ii) that, in contrast to spectra of the $\mathrm{Ti} / \mathrm{Zn}-\mathrm{ZnO}$ surface that are perfectly decomposed into $\mathrm{ZnO}$ and $\mathrm{Zn}$ components (Fig. $2 \mathrm{~b}$ ), spectra recorded on Ti/O-ZnO cannot be fitted by such a linear combination (Fig. $2 \mathrm{c}$ ). Significant extra-contributions centered at $\mathrm{BE} \sim 496 \mathrm{eV}$ and $\mathrm{BE} \sim 493 \mathrm{eV}$ are present (shaded areas in Fig. 2a and $2 \mathrm{c}$ ). These are assigned to the formation of an additional $\mathrm{Zn}$ species, which is assumed to be related to the formation of a ( $\mathrm{Ti}, \mathrm{Zn}, \mathrm{O})$ compound, herein labelled as TZO, having an intermediate $\mathrm{Ti}$ chemical shift. The decrease in intensity of the relative area of this extra-contribution upon increasing Ti thickness indicates that the corresponding $\mathrm{Zn}$ species lies at the Ti/ZnO interface. 


\section{Band-bending as a reporter of the Ti/ZnO interaction at the onset of growth}

The deposition of Ti on the two polar orientations of $\mathrm{ZnO}$ produces quite different changes in bandbending (BB). Fig. 3 shows the energy position of the $\mathrm{Zn} 2 p_{3 / 2}$ and $\mathrm{O} 1 \mathrm{~s}$ peaks (Fig. $3 \mathrm{a}$ and $3 b$, respectively) before and after depositing $d_{n o m}=1 \AA$ of Ti. The $Z n 2 p_{3 / 2}$ and $O$ is lines recorded on the clean $\mathrm{O}-\mathrm{ZnO}$ are found at $0.3 \mathrm{eV}$ toward lower $\mathrm{BE}$ relative to those observed on $\mathrm{Zn}-\mathrm{ZnO}$, which is due to a different space-charge layer formed at the two polar surfaces ${ }^{47,48}$. On O-ZnO, the Ti deposition induces a sizeable BE shift on the $\mathrm{Zn} 2 p_{3 / 2}$ and $\mathrm{O}$ 1s core-levels towards higher binding

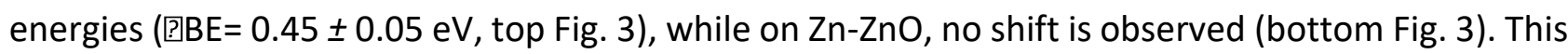
points to a Ti-induced downward $\mathrm{BB}$ on the O-ZnO surface and an absence of $\mathrm{BB}$ on the $\mathrm{Zn}$-ZnO surface. The present trend is further confirmed by the decomposition of $\mathrm{Zn} \mathrm{L}_{3} \mathrm{M}_{45} \mathrm{M}_{45}$ spectra of Fig. 2a. In the case of the linear combination used for fitting the Ti/Zn-ZnO spectrum (bottom part of Fig. 2a), the spectrum of bare $\mathrm{Zn}-\mathrm{ZnO}$ does not display any energy shift upon the $\mathrm{Ti}$ deposition of $d_{n o m}=1 \AA$. In contrast, the best fit of the Ti/O-ZnO spectrum (top part of Fig. 2a) results in an energy shift of the bare O-ZnO by $+0.15 \mathrm{eV}$, i.e. in the same direction as the BB for $\mathrm{Zn} 2 p$. By applying a $+0.4 \mathrm{eV}$ shift as observed for the core levels (Fig. 3), the curve fitting degrades, which further confirms the assumption of an extra oxidation state other than that of metallic $\mathrm{Zn}$ or $\mathrm{ZnO}$.

Comparable BBs, and somehow orientation-dependent chemistry have already been observed upon atomic $\mathrm{H}$ adsorption on the basal $\mathrm{ZnO}$ surfaces ${ }^{49-54}$. On $\mathrm{Zn}-\mathrm{ZnO}$, Becker and coworkers ${ }^{50,51}$ highlighted the instability of this surface upon atomic hydrogen exposure. Whereas the substrate keeps a $(1 \times 1)$ LEED pattern, helium atom scattering $(H A S)^{50,51}$ and photoemission ${ }^{49}$ evidenced the formation of $\mathrm{OH}$ groups through the breaking of the $\mathrm{Zn}-\mathrm{O}$ back bonds. A prolonged exposure destroyed the periodicity as seen by HAS but not by LEED proving that this surface reduction is limited to the top surface layers. Somehow similar findings were made by near field microscopies and spectroscopic ellipsometry ${ }^{52-54}$ but at much higher exposure. These measurements revealed that the $\mathrm{Zn}-\mathrm{ZnO}$ is easily etched by atomic hydrogen giving rise to a surface roughening. The signatures of metallic $\mathrm{Zn}$ and $\mathrm{OH}$ are also observed by photoemission ${ }^{49}$. At the opposite, the O-ZnO surface passivates upon the formation of an $\mathrm{H}$-covered surface ${ }^{49}$. From ellipsometry and AFM, no changes

are observed on the O-terminated surface $\mathrm{e}^{52,53}$. The difference of reactivity of the two surfaces stems from the bonding strength between $\mathrm{O}-\mathrm{H}$ and $\mathrm{Zn}-\mathrm{H}^{55}$. Besides the loss of atomic structure, similar considerations can be applied to the case of the Ti adsorption on $\mathrm{Zn}-\mathrm{ZnO}$, Ti adatoms interact with $\mathrm{O}$ atoms of the second layer of $\mathrm{Zn}-\mathrm{ZnO}$ by "etching" the $\mathrm{Zn}$ atoms of the first layer which then form metallic $\mathrm{Zn}$. The substitution of $\mathrm{Zn}$ ions by Ti ions has formally no effect on surface dipoles. Consistently, it does not entail any change in BB (Fig. 3, bottom spectra). On the contrary, on the O$\mathrm{ZnO}$, Ti adatoms bond directly to surface $\mathrm{O}$ atoms without altering the $\mathrm{O}-\mathrm{Zn}$ stacking, which results in a charge transfer from the $\mathrm{Ti}$ atoms to the oxide and causes a downward BB (Fig. 3, top spectra). Quite remarkably, a similar picture was proposed for $\mathrm{Pt} / \mathrm{ZnO}$ interfaces. At the Pt/Zn$\mathrm{ZnO}$ interface, the observation of metallic $\mathrm{Zn}$ points to a partial reduction of the oxide. In contrast, no such reduction occurs for $\mathrm{Pt} / \mathrm{O}-\mathrm{ZnO}$ (while $\mathrm{Pt}-\mathrm{O}$ bonds are evidenced without any disruption of $\mathrm{Zn}-\mathrm{O}$ bonds $)^{22}$. In present experiments, a partial substitution of hydroxyls groups that are known to exist on $\mathrm{O}-\mathrm{ZnO}$ as due to residual background pressure cannot be ruled out ${ }^{39-41}$ as it was already shown on alumina surfaces ${ }^{56}$. 
A main consequence of the above description of the Ti/ZnO interfaces is the orientation-dependent chemistry of $\mathrm{Ti}$ on the two $\mathrm{ZnO}$ polar surfaces. On $\mathrm{Zn}-\mathrm{ZnO}$, the etching of the surface $\mathrm{Zn}$ atoms by Ti adatoms suggested by the absence of BB leads to a formal substitution of $\mathrm{Zn}$ by Ti via the reaction:

$$
\mathrm{Ti}+2 \mathrm{ZnO} \rightarrow \mathrm{TiO}_{2}+2 \mathrm{Zn}
$$

The exclusive existence of only two states of zinc revealed by the $\mathrm{Zn}$ LMM transition (Fig. 2) corroborates this scenario, as well as the degree of oxidation of Ti which, at a coverage of $1 \AA$, is mostly in the $\mathrm{Ti}^{4+}$ form (71\%) vs $19 \%$ and $9 \%$ for $\mathrm{Ti}^{3+}$ and $\mathrm{Ti}^{2+}$, respectively (Fig. 1).

On O-ZnO, the sharp variation in BB provides a framework to understand the main aspects of what is going on at the $\mathrm{Ti} / \mathrm{ZnO}$ interface. The downward $\mathrm{BB}$ observed at the onset of the Ti deposition indicates that $\mathrm{Ti}$ adatoms sit on surface $\mathrm{O}$ atoms to create dipoles that can be formally represented as $\mathrm{Ti}^{\mathrm{Q}+}-(\mathrm{O}-\mathrm{Zn})^{\mathrm{Q}-}$. Consistently, the extra-components seen in the $\mathrm{Zn} \mathrm{L}_{3} \mathrm{M}_{45} \mathrm{M}_{45}$ Auger spectra reveal that $\mathrm{Ti}$ reacts with $\mathrm{ZnO}$ to produce a TZO interfacial compound (Fig. 2a and 2c). In such a compound, the sharing of $\mathrm{O}$ atoms leads to an average formula $\mathrm{TiZn}_{x} \mathrm{O}_{y}$ in which $y$ is likely greater than $x^{57}$. As a consequence, the reduction of $\mathrm{ZnO}$ is expected to parallel the formation of the TZO compound, in a reaction of the form:

$$
\mathrm{Ti}+y \mathrm{ZnO} \rightarrow \mathrm{TiZn}_{x} \mathrm{O}_{y}+(y-x) \mathrm{Zn}
$$

For a Ti/O-ZnO coverage of $1 \AA$, the sum of the contributions $\mathrm{Ti}^{3+}(28 \%)$ and $\mathrm{Ti}^{2+}(23 \%)$ of the $\mathrm{Ti} 2 p$ spectra is equivalent to the $\mathrm{Ti}^{4+}$ component (48\%) (Fig. 1), this is indicative of an average degree of oxidation of titanium of 3.2 which is smaller than 4 , in particular smaller than in the case of Ti/Zn$\mathrm{ZnO}$. The formation of the TZO compound explains the relatively moderate oxidation of the $\mathrm{Ti}$ adlayer.

\section{Orientation-dependent depth profile of chemical states}

To understand the behavior of the Ti/ZnO films upon increasing Ti thickness, the analysis of the XPS data recorded at $d_{\text {nom }}=4 \AA$ is of particular interest. At this coverage, the relative amount of metallic Ti does not yet completely overcome that of the oxidized Ti species (Fig.1b) so that the depth profile can be described by the comparison of normal and grazing ( $60^{\circ}$ off-normal) emission photoemission spectra (NE and GE, respectively). The vertical depth profile of the Ti and $\mathrm{Zn}$ species is explored by comparing the relative intensity of $\mathrm{Ti} 2 p$ and $\mathrm{Zn} \mathrm{L}_{2} \mathrm{M}_{45} \mathrm{M}_{45}$ spectra (Fig. 4). The $\mathrm{Zn} \mathrm{L}_{2} \mathrm{M}_{45} \mathrm{M}_{45}$ Auger line involves the same shallow levels as the $\mathrm{Zn} \mathrm{L}_{3} \mathrm{M}_{45} \mathrm{M}_{45}$ though the Ti $2 p_{1 / 2}$ core-hole replaces Ti $2 p_{3 / 2}$. Despite its lower intensity, the $Z_{n} L_{2} M_{45} M_{45}$ has the decisive advantage to make comparisons between NE and GE easier; its proximity to Ti $2 p$ when using $\mathrm{Al} \mathrm{K}_{\mathrm{B}} \mathrm{X}$-rays excitation leads to electrons with similar kinetic energies. Therefore, this $B E$ region has been chosen for the systematic study of depth profiles of the $4 \AA$ thick Ti/ZnO films, both after deposition at 300 $\mathrm{K}$ (Fig. 4a) and upon annealing (Fig. $4 \mathrm{~b}$ and $4 \mathrm{c}$ ). The Ti $2 p$ spectra are normalized to the same area for the two emission angles, which allows for the straight comparison of the Ti components as well as the $\mathrm{Zn} \mathrm{L}_{2} \mathrm{M}_{45} \mathrm{M}_{45} / \mathrm{Ti} 2 p$ area ratio.

On the $4 \AA$ thick Ti/Zn-ZnO film after deposition at $300 \mathrm{~K}$ (bottom spectra of Fig. 4a), the profile of the $\mathrm{Ti} 2 p$ spectrum does not change from NE to GE. The absence of angular-dependence 
demonstrates that all $\mathrm{Ti}$ species, $\mathrm{Ti}^{4+}, \mathrm{Ti}^{3+}, \mathrm{Ti}^{2+}$ and $\mathrm{Ti}^{0}$, are uniformly distributed across the $\mathrm{Ti}$ layer.

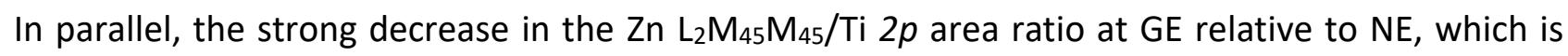
mainly due to the decrease in intensity of peak $A_{o x}$, shows that the $\mathrm{Zn}$ - $\mathrm{ZnO}$ substrate is covered by a partially oxidised $\mathrm{Ti}$ adlayer. In addition, the slight increase in intensity of $\mathrm{B}_{\text {met }}$ indicates that $\mathrm{Zn}$ tends to diffuse outward. The situation changes dramatically for Ti/O-ZnO (Fig. 4a, top spectra). At $\mathrm{GE}$, the considerable increase of the spectral weight of $\mathrm{Ti}^{4+}$ with respect to that of the other species $\left(\mathrm{Ti}^{0}, \mathrm{Ti}^{2+}\right.$ and $\mathrm{Ti}^{3+}$ ) proves that $\mathrm{Ti}^{4+}$ lies on top of the $\mathrm{Ti}$ film. The $\mathrm{Zn} \mathrm{L}_{2} \mathrm{M}_{45} \mathrm{M}_{45} / \mathrm{Ti} 2 p$ area ratio also contrasts with the $\mathrm{Ti} / \mathrm{Zn}$ - $\mathrm{ZnO}$ case. It increases at $\mathrm{GE}$, which is due to the relative raise in intensity of the peak $A_{o x}$, while the intensity of $B_{\text {met }}$ slightly decreases. The $\mathrm{Zn}$ lying at the surface of Ti / O$\mathrm{ZnO}$ is therefore oxidized. Although it is not possible to determine whether it belongs to pure $\mathrm{ZnO}$ or to a TZO compound involving $\mathrm{Ti}^{4+}$, it is demonstrated that, at the extreme surface, (i) the degree of oxidation of $\mathrm{Ti}$ increases and that (ii) the oxidized $\mathrm{Ti}$ is accompanied by oxidized $\mathrm{Zn}$. Interestingly, the decomposition of the $\mathrm{Zn}_{3} \mathrm{M}_{45} \mathrm{M}_{45}$ spectra indicates that the area of the extra contribution assigned to TZO (shaded areas in Fig. 2a and 2c) decreases from NE to GE, thus suggesting that the oxidized $\mathrm{Zn}$ at surface has not the same chemical environment as in the interfacial TZO compound. The present observations are sketched in Fig. 5a, which represents, in a very simplified way, the depth profiles of the Ti-Zn layers on the two $\mathrm{ZnO}$ polar orientations.

\section{Annealing $\mathrm{Ti} / \mathrm{ZnO}$ interfaces}

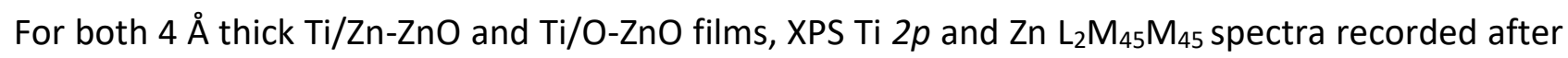
annealing at different temperatures show a progressive oxidation of $\mathrm{Ti}_{\text {into }} \mathrm{Ti}^{4+}$ (Fig. $4 \mathrm{~b}$ ). In parallel, the $01 s$ spectra (Fig. 6) reveal an enrichment in oxygen of the top layer. The oxidation process is therefore related to migration of oxygen towards the surface. Upon increasing the annealing temperature, the component Bmet disappears, while component Aox slightly increases. The likely reason is the progressive desorption of the metallic $\mathrm{Zn}$. For comparison, the metallic $\mathrm{Zn} / \mathrm{Al}_{2} \mathrm{O}_{3}(0001)$ film is readily removed from the alumina surface below $600 \mathrm{~K}$ due to the high vapour pressure of metallic zinc ${ }^{45,46}$. Noteworthy, the extra contribution observed in the $\mathrm{Zn}_{2} \mathrm{M}_{45} \mathrm{M}_{45}$ and $\mathrm{Zn} \mathrm{L}_{3} \mathrm{M}_{45} \mathrm{M}_{45}$ spectra upon Ti deposition on O-ZnO (Fig. 2a and 2c) disappears after annealing at $1000 \mathrm{~K}$.

The spectra taken at NE after annealing at $1000 \mathrm{~K}$ show that, on both surfaces, the overlayer involves $\mathrm{Ti}$ and $\mathrm{Zn}$ species at their highest degree of oxidation (Fig. 4b). However, the annealed films of the two terminations differ in the vertical distribution of the $\mathrm{Zn}$ and Ti species. The angledependent photoemission spectra of the samples annealed at $1000 \mathrm{~K}$ are shown in Fig. 4c. On $\mathrm{Zn}-\mathrm{ZnO}$, the Ti $2 p$ profile does not change from NE to $\mathrm{GE}$, while the Ti $2 p / \mathrm{Zn} \mathrm{L}_{2} \mathrm{M}_{45} \mathrm{M}_{45}$ intensity ratio strongly increases. Thus the probed $\mathrm{Ti}$ depth is mostly composed by $\mathrm{Ti}^{4+}\left(\mathrm{TiO}_{2}\right)$, while the oxidized $\mathrm{Zn}$ remains confined to the substrate below. On OZnO, neither the Ti $2 p$ profile nor the $\mathrm{Ti} 2 p / Z n L_{2} \mathrm{M}_{45} \mathrm{M}_{45}$ ratio change from NE to $\mathrm{GE}$ which reveals the occurrence of a defined TZO compound; the perfect overlapping NE and GE spectra implies that the sole ZnO substrate is never detected. Thus, Ti has diffused into the ZnO substrate over the depth probed by XPS at $\mathrm{NE}$, which is around 1-2 $\mathrm{nm}$ for $\mathrm{KE}=1020 \mathrm{eV}$. In other words, the TZO formation extends well beyond the nominal Ti thickness of $4 \AA$ and implies interdiffusion of $\mathrm{Ti}, \mathrm{Zn}$ and $\mathrm{O}$. Notably, the trend observed at the onset of the deposition of Ti, i.e. the prevalence of $\mathrm{Ti}^{4+}$ on $\mathrm{Zn}-\mathrm{ZnO}$ and the presence of a TZO compound at O-ZnO, is confirmed on thicker films upon annealing. 
At the level of the photoemission, the nature of the formed compound can only be hypothesized; on the basis of the oxidation states of $\mathrm{Ti}$ and $\mathrm{Zn}$, $\mathrm{Zn}$ ortho-titanate spinel $\left(\mathrm{Zn}_{2} \mathrm{TiO}_{4}\right)$, $\mathrm{Zn}$ polytitanate defective spinel $\left(\mathrm{Zn}_{2} \mathrm{Ti}_{3} \mathrm{O}_{8}\right)$ and $\mathrm{Zn}$ meta-titanate $\left(\mathrm{ZnTiO}_{3}\right.$, hexagonal ilmenite structure) are potential candidates accordingly to the known compounds and the phase diagram of $\mathrm{TiO}_{2} / \mathrm{ZnO}^{6,57,58}$. Annealing-induced interdiffusion at the interface of metal oxides is a recurrent mechanism for spinel formation, but the phenomenon is generally studied only at microscopic level ${ }^{59-61}$. The spinel phase has been previously hypothesized on sputter-deposited $\mathrm{ZnO} / \mathrm{Ti} / \mathrm{ZnO}$ coatings annealed at $900 \mathrm{~K}^{13,37}$ as well as at the $\mathrm{Cr} / \mathrm{O}-\mathrm{ZnO}$ interface and at the $\mathrm{Fe} / \mathrm{Zn}-\mathrm{ZnO}$ interface upon annealing at $830 \mathrm{~K}^{34,35}$ and 820-870 $\mathrm{K}^{36}$,respectively. Interestingly, a thin zinc oxide layer above metallic chromium is observed at room temperature for $\mathrm{Cr} / \mathrm{O}-\mathrm{ZnO}$, in analogy to our results ${ }^{34,35}$. Finally, the activation temperature for the $\mathrm{Ti}$ oxidation dramatically differs for the two polar surfaces. On O-ZnO, the reaction onsets below $500 \mathrm{~K}$ and is completed at $700 \mathrm{~K}$ (Fig. 4b). Conversely, on $\mathrm{Zn}-\mathrm{ZnO}$, the oxidation process is activated above $700 \mathrm{~K}$ and is almost completed at $1000 \mathrm{~K}$ (Fig. 4b). In parallel, on both surfaces, the oxygen enrichment of the film (Fig. 6) is activated for similar temperature ranges as for the Ti oxidation. The formation of the spinel observed only on O-ZnO and not on $\mathrm{Zn}$ $\mathrm{ZnO}$ as well as the lower activation temperature may be explained by different space charge layers ${ }^{47,48}$ at the two surfaces of $\mathrm{ZnO}$ that much favours out-diffusion of oxygen and inwards diffusion of $\mathrm{Ti}$ on O-ZnO. Similar arguments have been put forward to explain strong metal support interaction phenomena ${ }^{62}$ as well as change in wetting of $\mathrm{Cu}$ on $\mathrm{ZnO}^{40}$.

\section{Conclusion}

Different reactive behaviours of titanium with the two polar faces of $\mathrm{ZnO}$ have been observed. At submonolayer Ti coverage, changes in band-bending that compare to those produced by hydrogen adsorption are observed. They stem from the orientation-dependent $\mathrm{Ti} / \mathrm{ZnO}$ surface chemistry. On $\mathrm{Zn}-\mathrm{ZnO}$, Ti reduces $\mathrm{ZnO}$ to form a Ti oxide, while on $\mathrm{O}-\mathrm{ZnO}$, the deposition of Ti gives rise to the formation of a ( $\mathrm{Ti}, \mathrm{Zn}, \mathrm{O})$ compound. A similar chemistry is observed upon annealing the Ti adlayers, although with very different activation temperatures, $500 \mathrm{~K}$ on O-ZnO and $700 \mathrm{~K}$ on $\mathrm{Zn}$ - ZnO. Those orientation-dependent behaviours are expected to strongly affect applications relying either on rather thin $\mathrm{Ti} / \mathrm{ZnO}$ films or on surface properties that depend on the charge compensation mechanism at the interface of the adlayer with polar $\mathrm{ZnO}$ substrates $^{63}$. The present results also partly explain why $\mathrm{Ti} / \mathrm{ZnO}$ electrical contact properties are quite scattered and depend on annealing treatments and crystal orientation ${ }^{1}$.

\section{Acknowledgments}

This work was supported by grants from the ANR, project COCOTRANS: ANR-2011-RMNP-010-02, from Erasmus Mundus Action 2, Erasmus Mundus Maghreb, No.2012-2623 and from the Chinese Scholarship Council: No.201406150013. P. B. acknowledges financial support by the European Union's Horizon 2020 research and innovation programme under the Marie Sklodowska-Curie grant agreement No.658056. 


\section{References}

${ }^{1}$ L. J. Brillson and Y. Lu, J. Appl. Phys., 2011, 109, 121301.

2 E. V. Monakhov, A. Y. Kuznetsov and B. G. Svensson, J. Phys. D: Appl. Phys., 2009, 42, 153001.

${ }^{3}$ X. Huang, L. Zhang, S. Wang, D. Chi and S. J. Chua, ACS Appl. Mater. Interfaces, 2016, 8, 1548215488.

${ }^{4}$ X. Huang, R. Chen, C. Zhang, J. Chai, S. Wang, D. Chi and S. J. Chua, Adv. Opt. Mater., 2016, 4, 960966.

${ }^{5}$ M. M. Brewster, X. Zhou, S. K. Lim and S. Gradecak, J. Phys. Chem. Lett., 2011, 2, 586-591.

${ }^{6}$ H.-K. Kim, S.-H. Han, T.-Y. Seong and W.-K. Choi, Appl. Phys. Lett., 2000, 77, 1647.

${ }^{7}$ K. Ip, K. M. Baik, Y. W. Heo, D. P. Norton, S. J. Pearton, J. R. LaRoche, B. Luo, F. Ren and J. M. Zavada, J. Vac. Sci. Technol., B, 2003, 21, 2378.

${ }^{8}$ B. S. Kang, J. J. Chen, F. Ren, Y. Li, H.-S. Kim, D. P. Norton, S. J. Pearton, Appl. Phys. Lett., 2006, 88, 2101.

${ }^{9}$ C.-L. Tsai, Y.-J. Lin, Y.-M. Chin, W.-R. Liu, W. F. Hsieh, C.-H. Hsu and J.-A. Chu, J. Phys. D: Appl. Phys., 2009, 42, 095108.

${ }^{10}$ R. Khanna, E. A. Douglas, D. P. Norton, S. J. Pearton, F. Ren et al., J. Vac. Sci. Technol., B, 2010, 28, L43-L46.

${ }^{11}$ P. Joshi, J. Singh, S. Das, J. V. Desai and J. Akhtar, AIP Conf. Proc., 2016, 1724, 020070.

12 H. S. Yang, D. P. Norton, S. J. Pearton and F. Ren, Appl. Phys. Lett., 2005, 87, 212106.

${ }^{13}$ R. Knut, R. Lindblad, S. Grachev, J.-Y. Faou, M. Gorgoi, H. Rensmo, E. Søndergård and O. Karis, J. Appl. Phys., 2014, 115, 043714.

${ }^{14}$ S. Y. Grachev, A. Mehlich, J.-D. Kamminga, E. Barthel and E. Søndergård, Thin Solid Films, 2010, 518, 6052-6054.

${ }^{15}$ D. Chakraborty, R. Gayen, S. Hussain, R. Bhar, A. K. Ghoshal and A. K. Pal, J. Phys.: Conf. Ser., 2012, 390, 012065.

${ }^{16}$ Y. Lai, W. Qiu, Z. Zeng, S. Cheng, J. Yu and Q. Zheng, Nanomaterials, 2016, 6, 16.

17 P. S. Shewale and Y. S. Yu, J. Alloys Compd., 2016, 684, 428-437.

18 S. Roberts and R. J. Gorte, J. Chem. Phys., 1990, 93, 5337-5344.

${ }^{19}$ W. T. Petrie and J. M. Vohs, J. Chem. Phys., 1994, 101, 8098-8107.

${ }^{20}$ P. V. Radulovic, C. S. Feigerle and S. H. Overbury, J. Phys. Chem. B,2000, 104, 3028-3034.

${ }^{21}$ T. Nagata, J. Volk, Y. Yamashita, H. Yoshikawa, M. Haemori, R. Hayakawa, M. Yoshitake, S. Ueda, K. Kobayashi and T. Chikyow, Appl. Phys. Lett., 2009, 94, 221904.

${ }^{22}$ M. Yoshitake, P. Blumentrit and S. Nemsak, J. Vac. Sci. Technol., A, 2013, 31, 020601.

${ }^{23}$ W. Gaebler, K. Jacobi and W. Ranke, Surf. Sci., 1978, 75, 355-367.

${ }^{24}$ I. Hegemann, A. Schwaebe and K. Fink, J. Comput. Chem., 2008, 29, 2302-2310.

25 B. Meyer and D. Marx, Phys. Rev. B, 2004, 69, 235420.

26 J. Yoshihara, J. M. Campbell and C. T. Campbell, Surf. Sci., 1998, 406, 235-245.

27 J. Yoshihara, S. C. Parker and C. T. Campbell, Surf. Sci., 1999, 439, 153-162.

${ }^{28}$ O. Dulub, M. Batzill and U. Diebold, Top. Catal., 2005, 36, 65-76.

${ }^{29}$ E. D. Batyrev, N. R. Shiju and G. Rothenberg, J. Phys. Chem. C, 2012, 116, 19335-19341.

${ }^{30}$ I. Beinik, M. Hellström, T. N. Jensen, P. Broqvist and J. V. Lauritsen, Nat. Commun., 2015, 6, 8845.

${ }^{31}$ N. Jedrecy, G. Renaud, R. Lazzari and J. Jupille, Phys. Rev. B, 2005, 72, 195404.

${ }^{32}$ N. Jedrecy, G. Renaud, R. Lazzari and J. Jupille, Phys. Rev. B, 2005, 72, 045430.

${ }^{33}$ E. F. Wassermann and K. Polacek, Appl. Phys. Lett., 1970, 16, 259-260. 
${ }^{34}$ M. Galeotti, M. Torrini, U. Bardi, A. Santucci and D. Ghisletti, Surf. Sci., 1997, 375, 63-70.

35 I. Spolveri, A. Atrei, B. Cortigiani, U. Bardi, A. Santucci and D. Ghisletti, Surf. Sci., 1998, 412, 631638.

${ }^{36}$ D. Wett, A. Demund, H. Schmidt and R. Szargan, Appl. Surf. Sci., 2008, 254, 2309-2318.

${ }^{37}$ E. Chernysheva, Ph.D. thesis, Université Pierre et Marie Curie - Paris VI, 2017.

38 O. Dulub, U. Diebold and G. Kresse, Phys. Rev. Lett., 2003, 90, 016102.

${ }^{39}$ C. Wöll, Prog. Surf. Sci., 2007, 82, 55-120.

40 J. V. Lauritsen, S. Porsgaard, M. K. Rasmussen, M. C. Jensen, R. Bechstein, K. Meinander, B. S. Clausen, S. Helveg, R. Wahl, G. Kresse et al., ACS nano, 2011, 5, 5987-5994.

${ }^{41}$ R. Wahl, J. V. Lauritsen, F. Besenbacher and G. Kresse, Phys. Rev. B, 2013, 87, 085313.

42 K. Maeda, M. Sato, I. Niikura and T. Fukuda, Semicond. Sci. Technol., 2005, 20, S49.

${ }^{43}$ http://www.casaxps.com.

44 J. H. Fox, J. D. Nuttall and T. E. Gallon, Surf. Sci., 1977, 63, 390-402.

${ }^{45}$ R. Cavallotti, Ph.D. thesis, Université Pierre et Marie CurieParis VI, 2014.

${ }^{46}$ H.-L. T. Le, R. Cavallotti, R. Lazzari, J. Goniakowski, C. Noguera, J. Jupille, A. Koltsov and J.-M. Mataigne, submitted.

${ }^{47}$ R. Heinhold, G. T. Williams, S. P. Cooil, D. A. Evans and M. W. Allen, Phys. Rev. B, 2013, 88, 235315.

${ }^{48}$ K. Jacobi, G. Zwicker and A. Gutmann, Surf. Sci., 1984, 141, 109-125.

${ }^{49}$ K. Ozawa and K. Mase, Phys. Rev. B, 2011, 83, 125406.

${ }^{50}$ T. Becker, S. Hövel, M. Kunat, C. Boas, U. Burghaus, and C. Wöll, Surf. Sci., 2001, 486, L502-L506.

${ }^{51}$ X.-L. Yin, A. Birkner, K. Hänel, T. Löber, U. Köhler and C. Wöll, Phys. Chem. Chem. Phys., 2006, 8, 1477-1481.

52 M. Losurdo and M. M. Giangregorio, Appl. Phys. Lett., 2005, 86, 091901.

53 G. Bruno, M. M. Giangregorio, G. Malandrino, P. Capezzuto, I. L. Fragalà and M. Losurdo, Adv. Mater., 2009, 21, 1700-1706.

${ }^{54}$ E. D. Batyrev and J. C. van den Heuvel, Phys. Chem. Chem. Phys., 2011, 13, 13127-13134.

${ }^{55}$ C. G. Van de Walle, Phys. Rev. Lett., 2000, 85, 1012.

${ }^{56}$ R. Lazzari and J. Jupille, Phys. Rev. B, 2005, 71, 045409.

${ }^{57}$ X. Qian, M.-Y. Gao, Y.-Q. Cao, B.-L. Guo and A.-D. Li, J. Vac. Sci. Technol., A, 2013, 31, 01 A133.

${ }^{58}$ F. H. Dulin and D. E. Rase, J. Am. Ceram. Soc., 1960, 43, 125-131.

${ }^{59}$ P. Zhang, T. Debroy and S. Seetharaman, Metall. Mater. Trans. A, 1996, 27, 2105-2114.

${ }^{60}$ K. P. Trumble and M. Rühle, Acta Mater., 1991, 39, 1915-1924.

${ }^{61}$ L. Hultman, J.-E. Sundgren and D. Hesse, J. Mater. Res., 1989, 4, 1266-1271.

62 Q. Fu and T. Wagner, Surf. Sci. Rep., 2007, 62, 431-498.

${ }^{63}$ X. Zhu, M. D. Morales-Acosta, J. J. Shen, F. Walker, J. J. Cha and E. I. Altman, Phys. Rev. B, 2015, 92, 165414. 


\section{Figures}
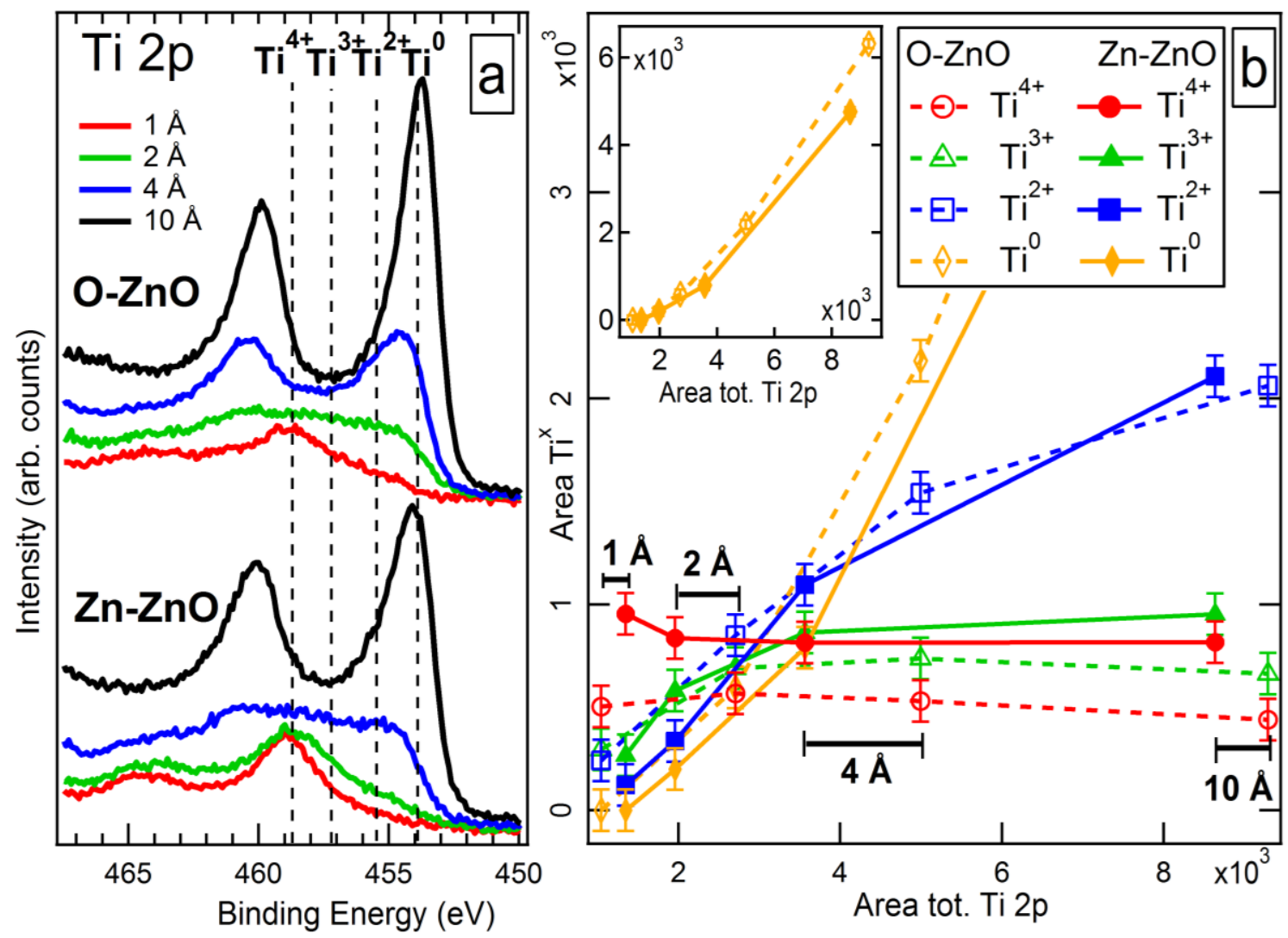

Fig. 1 XPS analysis of the Ti deposition on $\mathrm{ZnO}$ surfaces: a) Ti $2 p$ spectra on O-ZnO (top) and $\mathrm{Zn}$ - $\mathrm{ZnO}$ (bottom). Spectra are recorded at a nominal Ti thickness of $d_{n o m}=1 \AA$ (red), $2 \AA$ (green), $4 \AA$ (blue) and $10 \AA$ (black) and normalized to the same background on the low BE side ( $\sim 445 \mathrm{eV})$. The dotted vertical bars mark the $\mathrm{BE}$ of $\mathrm{Ti}^{4+}, \mathrm{Ti}^{3+}, \mathrm{Ti}^{2+}$ and $\mathrm{Ti}^{\circ}$ as deduced from the fit of the $\mathrm{Ti} 2 p$ spectrum of $\mathrm{d}_{\text {nom }}=1 \AA$ on the $\mathrm{Zn}-\mathrm{ZnO}$ (see ESI); b) Areas of $\mathrm{Ti}^{4+}$ (red), $\mathrm{Ti}^{3+}$ (green), $\mathrm{Ti}^{2+}$ (blue) and $\mathrm{Ti}^{0}$ (orange) components as a function of the Ti $2 p$ total area recorded on O-ZnO (empty markers, dotted line) and $\mathrm{Zn}-\mathrm{ZnO}$ (full markers, solid line) films. The corresponding nominal Ti thickness is indicated by the black horizontal bars. The full range of $\mathrm{Ti}^{\circ}$ values is reproduced in the inset. The $\mathrm{O}-\mathrm{ZnO}$ and $\mathrm{Zn}$ ZnO surfaces were exposed to identical stepwise Ti depositions of nominal thicknesses $d_{\text {nom }}=1 \AA, 2$ $\AA$ A $4 \AA$ and $10 \AA$. The Ti deposition had dramatic effects on both surfaces. The total disappearance of the LEED patterns from the initial stages of the film growth $\left(d_{\text {nom }}=1 \AA\right.$ ) indicates the loss of the ZnO surface crystallinity and the lack of long-range order for the Ti films. In parallel, the XPS Ti $2 p$ spectra recorded at normal emission demonstrate the high reactivity of Ti on both polar surfaces (Fig. 1a). According to the binding energy (BE) position of the peaks (vertical dotted lines in Fig. 1a, more details can be seen in ESI), the dominant species at the lowest coverage is $\mathrm{Ti}^{4+}$. Upon increasing the $\mathrm{Ti}$ thickeness, the lower $\mathrm{Ti}$ oxidation states (from $\mathrm{Ti}^{3+}$ to $\mathrm{Ti}^{0}$ ) progressively appear and, starting from $d_{\text {nom }}=4 \AA$, the $\mathrm{Ti}^{0}$ dominates the total composition of the $\mathrm{Ti}$. 


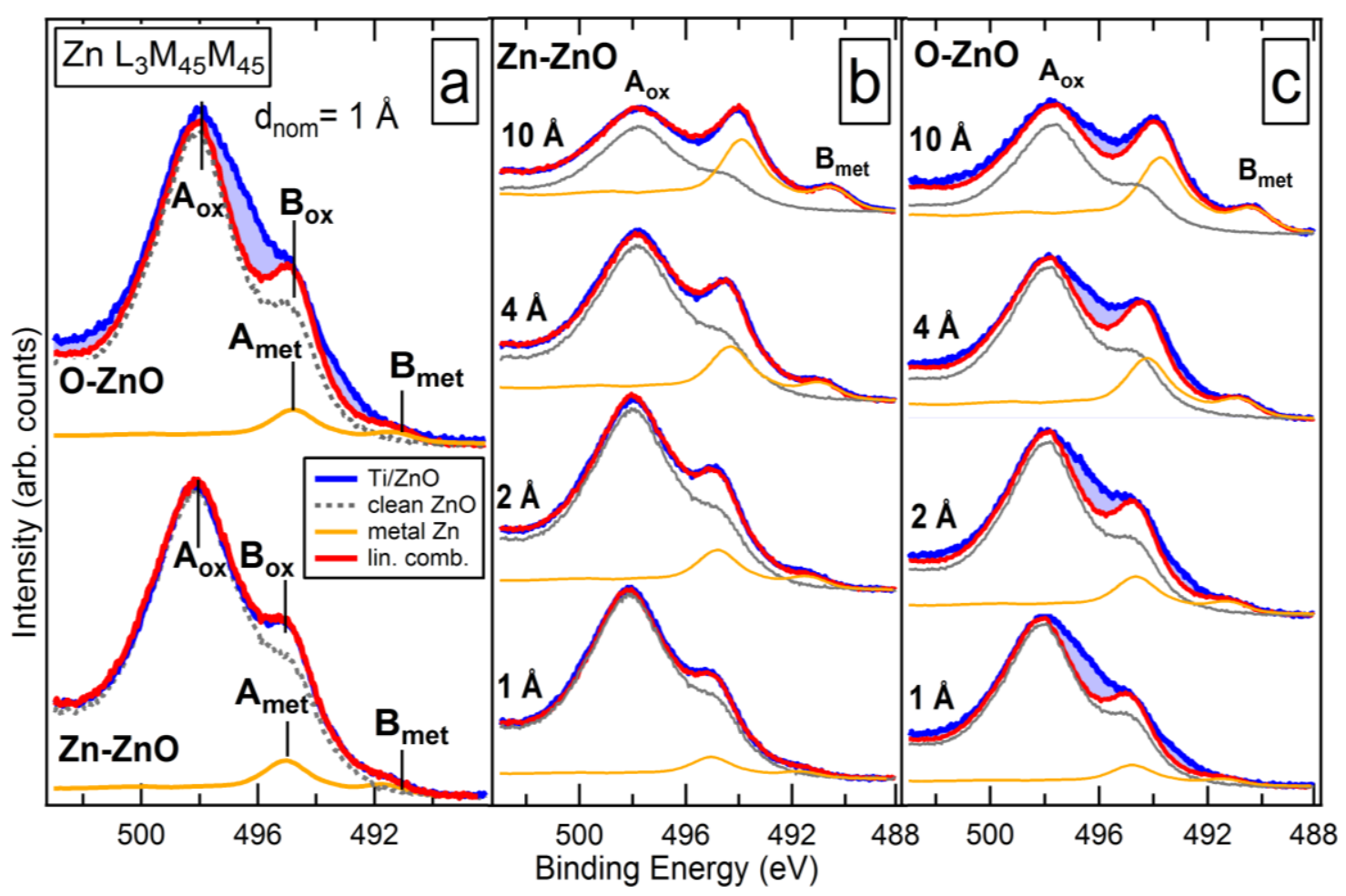

Fig. 2 Fit of $Z n L_{3} M_{45} M_{45}$ spectra (blue line) with a linear combination (red line) of the spectra of clean ZnO (dotted gray line) and metallic $\mathrm{Zn}$ (orange line): a) spectra obtained by depositing $\mathrm{d}_{\text {nom }}=$ $1 \AA$ Å of Ti on O-ZnO (top) and on $\mathrm{Zn}-\mathrm{ZnO}$ (bottom); b) set of spectra recorded for different Ti coverages (given in figure) on $\mathrm{Zn}-\mathrm{ZnO}$ and c) O-ZnO. In O-ZnO spectra, extra contributions that are not accounted for by the linear combination are marked by shaded areas. 


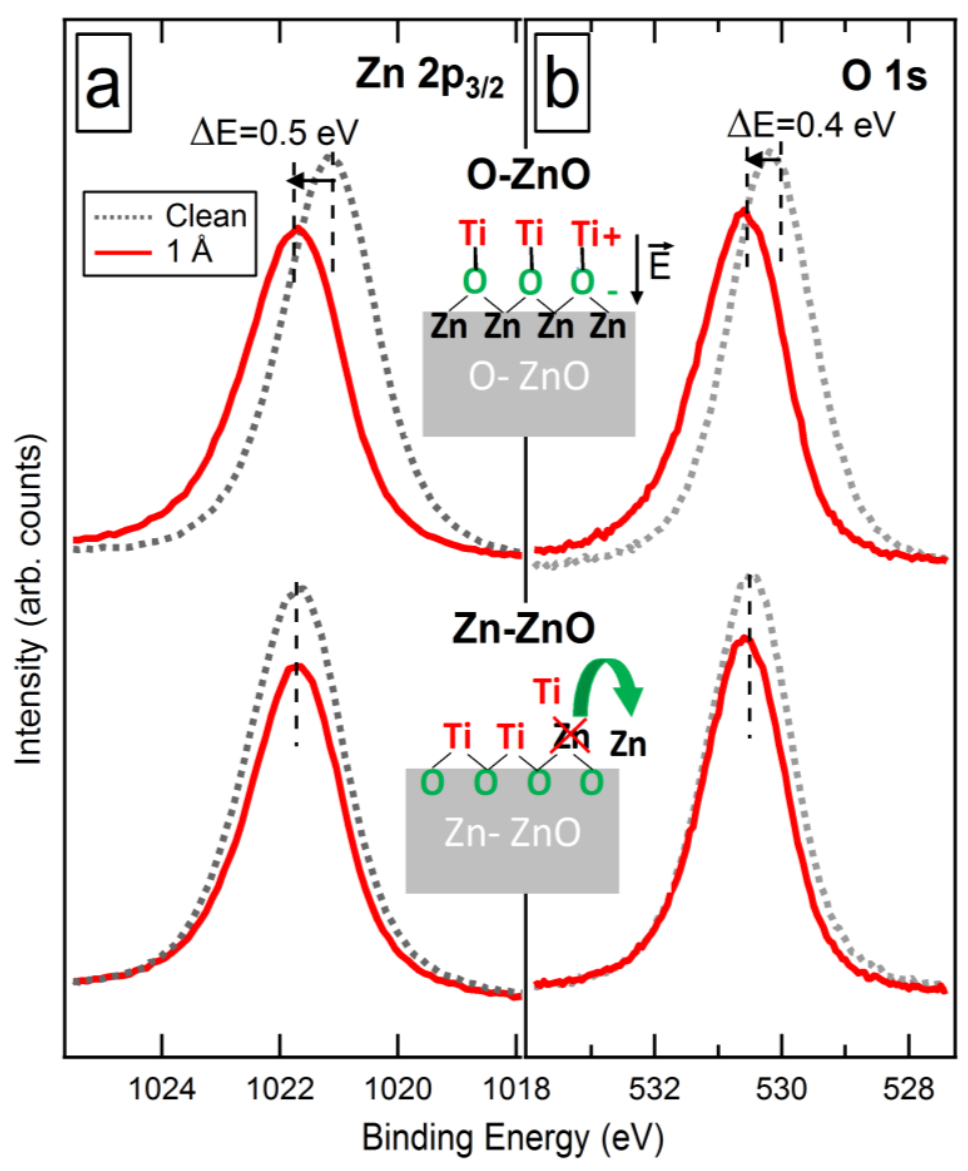

Fig. 3 XPS spectra of a) Zn $2 p_{3 / 2}$ and b) O 1s peaks before (grey lines) and after (red lines) depositing $\mathrm{d}_{\text {nom }}=1 \AA$ Af Ti. Spectra on O-ZnO and on $\mathrm{Zn}-\mathrm{ZnO}$ are shown in the top and bottom part of the figure, respectively. $\mathrm{Ti} / \mathrm{ZnO}$ reactions occurring on each termination are schematized in the figure. The peak shift on O-ZnO demonstrates a downward band-bending. 


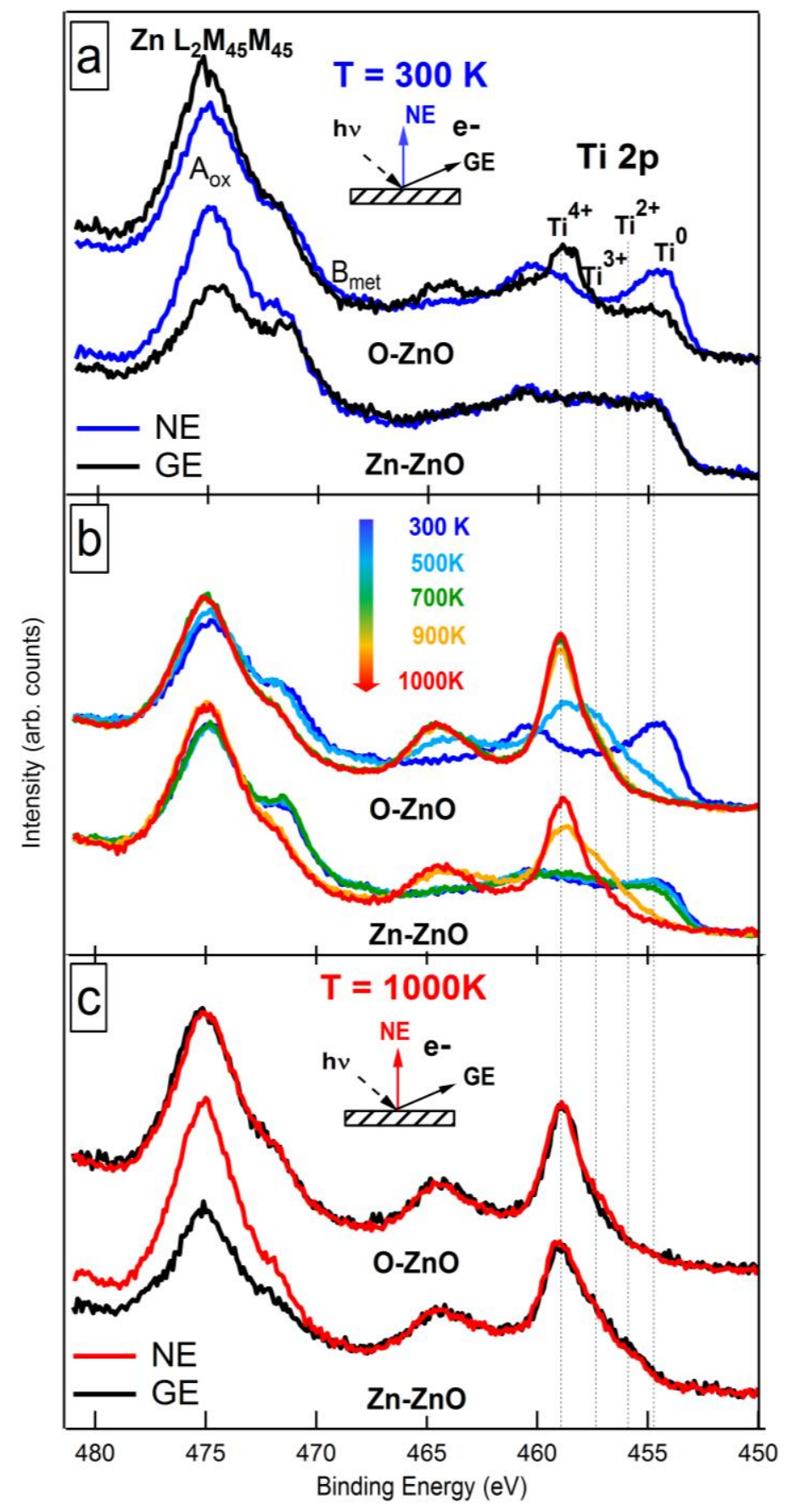

Fig. 4 Region of Ti $2 p$ and $\mathrm{Zn} \mathrm{L}{ }_{2} \mathrm{M}_{45} \mathrm{M}_{45}$ for the thickness $\mathrm{d}_{\text {nom }}=4 \AA$ of Ti deposited on O-ZnO (top) and on $\mathrm{Zn}-\mathrm{ZnO}$ (bottom). The spectra are taken at (a) normal emission (NE, blue) and grazing emission (GE, black) after deposition at room temperature, (b) upon annealing (NE) (c) at normal emission (NE, red) and grazing emission (GE, black) after annealing at $1000 \mathrm{~K}$. 


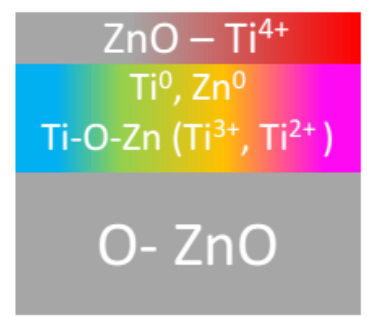

a)

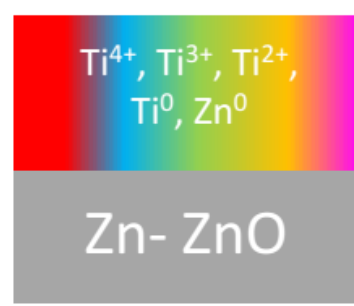

500-700 K

$\mathrm{Zn}_{2} \mathrm{TiO}_{4}$

$\mathrm{O}-\mathrm{ZnO}$

b)

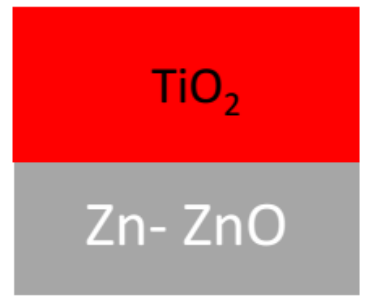

Fig. 5 Schematic depth profiles of Ti-Zn layer for the thickness $d_{n o m}=4 \AA$ of Ti deposited on $Z n-Z n O$ (bottom) and O-ZnO (top) a) before and b) after annealing (see text for explanations). 


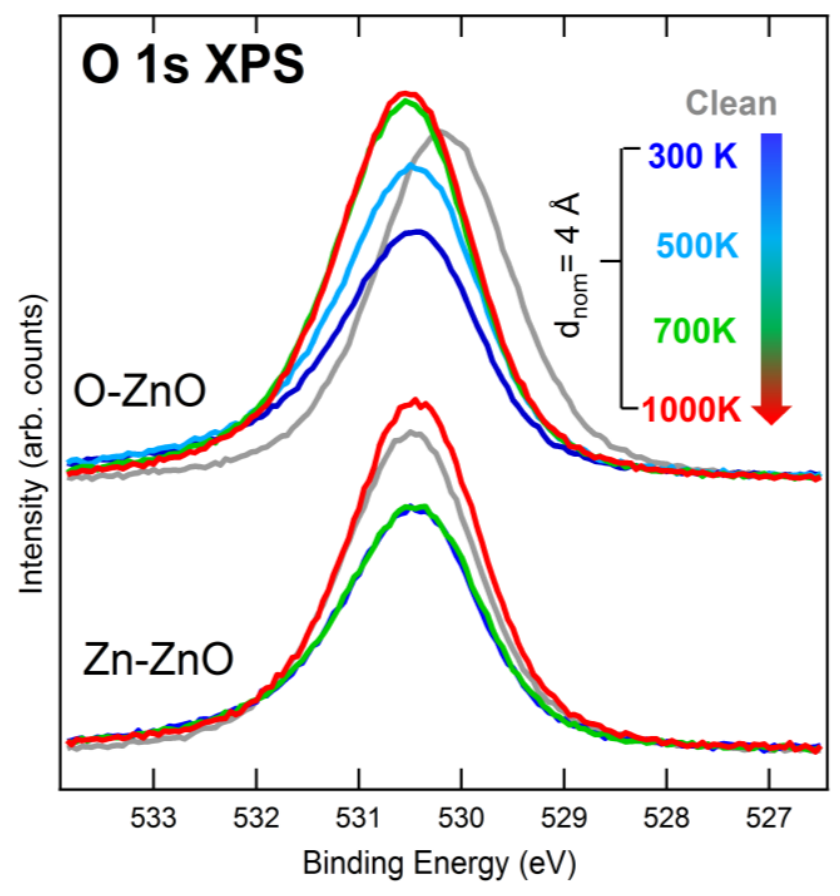

Fig. $601 \mathrm{~s}$ spectra for the thickness $d_{n o m}=4 \AA$ of Ti deposited on O-ZnO (top) and on $\mathrm{Zn}-\mathrm{ZnO}$ (bottom) upon annealing. 